\title{
PERBANDINGAN STABILITAS WARNA BASIS RESIN AKRILIK POLIMERISASI PANAS DENGAN RESIN NILON TERMOPLASTIS DALAM LARUTAN COKLAT
}

\author{
Fransiska Nuning Kusmawati*, Lintang Nitya Parathitaputri** \\ *Departemen Prostodonsia, Fakultas Kedokteran Gigi Universitas Prof. Dr. Moestopo (Beragama), Jakarta \\ **Fakultas Kedokteran Gigi Universitas Prof. Dr. Moestopo (Beragama), Jakarta \\ Korespondensi: Fransiska Nuning, nuningphynx@gmail.com
}

\begin{abstract}
ABSTRAK
Latar belakang: bahan yang digunakan untuk basis gigi tiruan yaitu resin akrilik polimerisasi panas dan nilon termoplastis. Kedua bahan tersebut memiliki kekurangan yang sama, yaitu penyerapan air yang tinggi sehingga dapat menyebabkan perubahan warna pada bahan basis gigi tiruan. Bahan dasar makanan dan minuman yang sering dikonsumsi manusia adalah coklat. Kandungan tanin dalam coklat dapat mempengaruhi perubahan warna pada basis gigi tiruan. Tujuan: penelitian ini bertujuan untuk mempelajari dan menjelaskan stabilitas warna plat basis resin akrilik polimerisasi panas dengan resin nilon termoplastis dalam larutan coklat. Metode Penelitian: pada penelitian ini digunakan 32 sampel yang terbagi dalam 2 kelompok resin akrilik polimerisasi panas dan resin nilon termoplastis yang direndam dalam $10 \mathrm{ml}$ larutan coklat selama 7 hari. Pengukuran warna dilakukan dengan alat VITA easyshade sebelum dan setelah perendaman.Data yang diperoleh terdiri dari value, chrome, dan hue lalu diolah menggunakan uji Wilcoxon dan Mann Whitney. Hasil: hasil perbandingan perubahan nilai warna basis gigi tiruan resin akrilik polimerisasi panas dan nilon termoplastis sebelum dan setelah perendaman dengan larutan coklat selama 7 hari menggunakan uji Mann Whitney menunjukkan hasil yang signifkan $(\mathrm{p}<0.05)$ untuk value senilai 0.008 , chroma 0.000 dan hue 0.000 . Terdapat penurunan rata-rata nilai value pada kelompok resin akrilik polimerisasi panas lebih besar dari pada resin nilon termoplastis, peningkatan rata-rata nilai chroma pada kelompok resin nilon termoplastis lebih besar dari pada resin akrilik polimerisasi panas, dan peningkatan rata-rata nilai hue pada kelompok resin nilon termoplastis lebih besar dari pada kelompok resin akrilik polimerisasi panas. Kesimpulan: plat resin akrilik polimerisasi panas lebih stabil terhadap perubahan warna dibandingkan dengan nilon termoplastis dalam perendaman larutan coklat selama 7 hari.
\end{abstract}

Kata kunci: Plat resin akrilik polimerisasi panas, plat resin nilon termoplastis, stabilitas warna

\begin{abstract}
Background: the materials used for denture base are heat polymerization acrylic resin and thermoplastic nylon. Both of the materials have high water absorption which can result in denture base discoloration. Denture base discoloration can caused by consumption of food and drink such as chocolate. Tannin composition in chocolate can affects denture base discoloration. Purpose: this study aims to study and explain the stability of the color of heat-polymerized acrylic resin plate with thermoplastic nylon resin plate in immersion of chocolate solution. Methods: In this study, 32 samples were divided into 2 groups of heat-polymerized acrylic resin and thermoplastic nylon resins which were immersed in $10 \mathrm{ml}$ of chocolate solution for 7 days. Color measurement is taken using VITA easyshade devices before and after immersion. The data obtained consisted of value, chroma, and hue and then processed using the Wilcoxon and Mann Whitney tests. Results: the results of the comparison of the changes in the color value of denture bases of acrylic resin with hot polymerization and thermoplastic nylon before and after soaking with brown solution for 7 days using the Mann Whitney test showed significant results $(p<0.05)$ for values worth 0.008 , chroma 0.000 and hue 0.000 . There is a decrease in the average value of the hot acrylic polymerization resin group is greater than in the thermoplastic nylon resin, an increase in the average chroma value in the thermoplastic nylon resin group is greater than the hot polymerization acrylic resin, and an increase in the average hue value in the group Thermoplastic nylon resins are larger than the hot polymerization acrylic resin group.Conclusion: the heat-polymerized acrylic resinplate is more stable to color changes than thermoplastic nylon that soaking in chocolate solution for 7 days.
\end{abstract}

Keywords: heat-polymerized acrylic resin plate, thermoplastic nylon resin plate, color stability 


\section{PENDAHULUAN}

$\mathrm{B}$ asis gigi tiruan adalah bagian dari gigi tiruan yang bersandar pada jaringan lunak dan tempat untuk elemen gigi tiruan dilekatkan. Basis juga merupakan bagian penting dari gigi tiruan karena berperan sebagai jaringan pendukung disekitar gigi yang berfungsi memperbaiki kontur jaringan sehingga dapat kembali menjadi seperti semula. ${ }^{1-2}$ Bahan basis gigi tiruan yang digunakan biasanya berasal dari resin. Beberapa resin yang digunakan dibidang kedokteran gigi yaitu resin akrilik dan resin nilon termoplastis. Masing-masing bahan tersebut mempunyai sifat yang menjadikannya sebagai pilihan utama sebagai bahan basis gigi tiruan. ${ }^{3}$

Bahan basis gigi tiruan yang sering dipakai adalah resin akrilik polimetil metakrilat jenis polimerisasi panas. Bahan ini juga memiliki kekurangan yaitu abrasi dan mudah patah bila terjatuh. Jangka waktu tertentu akan menunjukan kecenderungan menyerap air atau cairan. ${ }^{4}$ Bahan basis lainnya adalah resin nilon termoplastis yang memiliki banyak kelebihan dibandingkan dengan resin akrilik. Sifat estetiknya yang sangat baik dan biokompatibel menjadikan bahan ini lebih unggul. ${ }^{5}$ Basis gigi tiruan nilon termoplastis juga mempunyai sifat fisik yang menjadi kekurangannya yaitu pengerutan, perubahan dimensi dan penyerapan air yang tinggi. ${ }^{6}$

Stabilitas warna pada basis gigi tiruan ialah salah satu karakteristik utama yang sangat penting karena melibatkan masalah estetik. Teknik dan pemilihan bahan harus dipastikan agar meminimalisir terjadinya diskolorasi. Banyak faktor yang dapat menyebabkan terjadinya diskolorasi pada basis. Secara garis besar diskolorisasi pada basis gigi tiruan disebabkan oleh dua faktor, yaitu instrinsik dan ekstrinsik. Faktor instrinsik adalah perubahan kimia pada bahan itu sendiri yaitu proses polimerisasi yang tidak sempurna, sedangkan faktor ekstrinsik adalah munculnya stain akibat absorpsi bahan pewarna seperti dari kopi, coklat, nikotin, minuman ringan dan larutan kumur. ${ }^{7-9}$

Berdasarkan uraian di atas terdapat rumusan masalah apakah terdapat perbedaan stabilitas warna antara plat basis resin akrilik polimerisasi panas dan resin nilon termoplastis.

\section{METODE PENELITIAN}

Penelitian bersifat eksperimental laboratoris dengan pre-test dan post-test design. Penelitian dilakukan pada bulan Januari tahun 2018 di ruang Laboratoriun IMTKG Fakultas Kedokteran Gigi Universitas Prof. DR. Moestopo (Beragama). Bahan plat resin akrilik polimerisasi panas berjumlah 16 sampel berukuran $20 \times 10 \times 1 \mathrm{~mm}$ dan 16 plat resin nilon termoplastis berukuran $20 \times 10 \times 1 \mathrm{~mm}$. Penelitian ini telah lulus kaji etik dengan nomor: 006/ loloskajietik/FKG UPDM(B)/I/2019.
Tahap pertama menyiapkan alat dan bahan yang akan digunakai (gambar 1). Masing-masing sampel dibersihkan dengan air mengalir dandikeringkan. Lakukan pengukuran dengan alat uji VITA easyshade pada masing-masing sampel (pre-test).
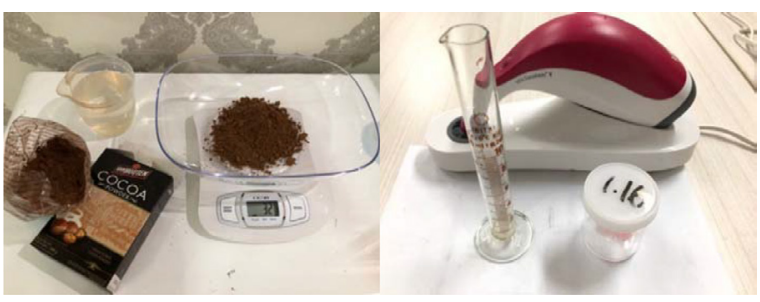

Gambar 1. Alat dan bahan yang digunakan

Pembuatan larutan coklat menggunakan seduhan berbentuk bubuk kemasan merk Van Houten yang dilarutkan dengan air panas $320 \mathrm{ml}$ bersuhu $100^{\circ} \mathrm{C}$ yang telah diukur menggunakan termometer. Larutan coklat didinginkan sampai bersuhu sama seperti suhu ruangan. Masukkan $10 \mathrm{ml}$ larutan coklat dalam wadah plastik (gambar 2).

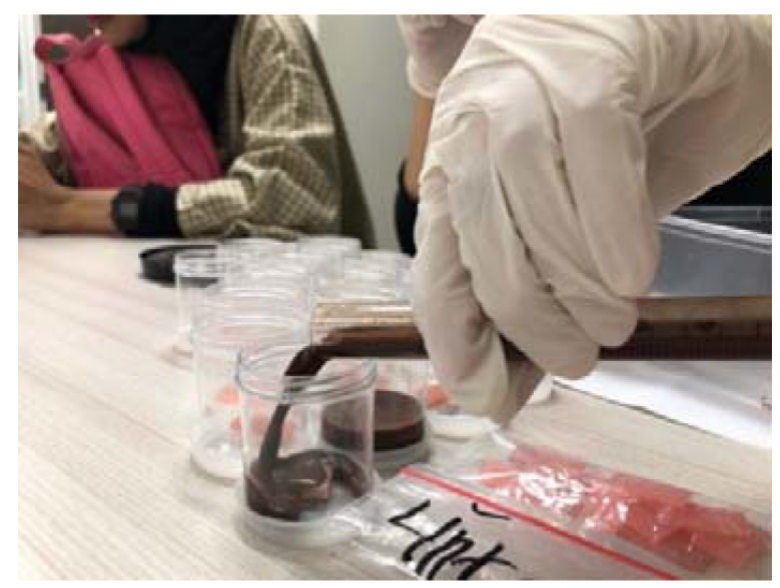

Gambar 2. Menuang larutan coklat $10 \mathrm{ml}$

Sampel penelitian resin akrilik dan resin nilon termoplastis dengan masing-masing 16 sampel dalam tiap kelompok. Kelompok I akrilik polimerisasi panas dalam perendaman larutan coklat dengan takaran 10 $\mathrm{ml}$. Kelompok II nilon termoplastis dalam perendaman larutan coklat dengan takaran $10 \mathrm{ml}$. Perendaman dilakukan dalam 24 jam selama 7 hari (gambar 3). Sampel yang telah direndam sesuai dengan waktunya, diangkat menggunakan pinset, dibilas dengan air dan dikeringkan. Letakkan pada nierbeken dan dilakukan pengukuran dengan alat uji VITA easyshade pada sampel dari masing-masing kelompok (post-test). Catat dan lakukan perbandingan skor warna sebelum dilakukan perendaman (pre-test) dan setelah dilakukan perendaman (post-test). 


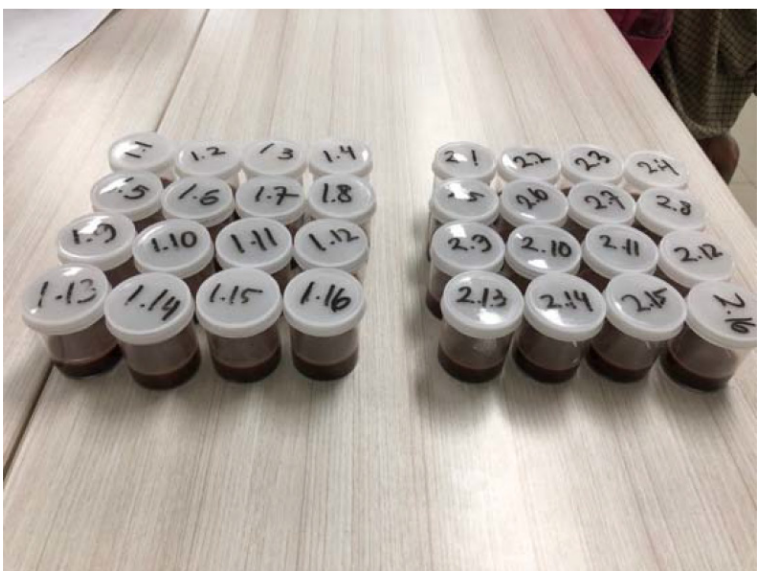

Gambar 3. Sampel direndam dalam larutan coklat

\section{HASIL PENELITIAN}

Tabel 1. Rata-rata nilai warna basis gigi tiruan resin akrilik polimerisasi panas sebelum dan setelah perendaman dengan larutan coklat selama 7 hari

\begin{tabular}{lccccc}
\hline $\begin{array}{c}\text { Resin Akrilik } \\
\text { Polimerisasi Panas }\end{array}$ & n & Min. & Max. & Mean & Std. Deviasi \\
\hline $\begin{array}{l}\text { Sebelum } \\
\quad \text { Value }\end{array}$ & & $-20,5$ & $-15,7$ & $-17,969$ & 1,2700 \\
$\quad$ Chroma & 16 & 4,4 & 6,3 & 5,363 & 0,6021 \\
$\quad$ Hue & & $-39,5$ & $-36,1$ & $-38,250$ & 1,0224 \\
Setelah & & & & & \\
$\quad$ Value & & $-22,2$ & $-17,6$ & $-19,888$ & 1,2516 \\
$\quad$ Chroma & 16 & 2,7 & 10,8 & 7,256 & 2,0775 \\
$\quad$ Hue & & $-38,1$ & $-31,3$ & $-34,681$ & 1,8741 \\
\hline
\end{tabular}

Tabel 1. menunjukkan bahwa terjadi perubahan warna sebelum dan setelah 7 hari perendaman larutan coklat pada basis gigi tiruan resin akrilik polimerisasi panas. Terjadi penurunan nilai rata-rata value, peningkatan rata-rata nilai chroma dan nilai hue.

Tabel 2. Rerata nilai warna basis nilon termoplastis sebelum dan setelah perendaman larutan coklat selama 7 hari

\begin{tabular}{lccccc}
\hline Nilon Termoplastis & n & Min. & Max. & Mean & Std. Deviasi \\
\hline Sebelum & & & & & \\
$\quad$ Value & & $-14,6$ & $-6,6$ & $-10,794$ & 2,1702 \\
$\quad$ Chroma & 16 & 1,0 & 6,5 & 4,125 & 1,6715 \\
$\quad$ Hue & & $-55,3$ & $-40,7$ & $-47,469$ & 4,0557 \\
& & & & & \\
Setelah & & & & \\
$\quad$ Value & & $-22,4$ & $-7,9$ & $-15,775$ & 4,4113 \\
$\quad$ Chroma & 16 & 5,0 & 14,9 & 11,169 & 2,8846 \\
$\quad$ Hue & & $-44,5$ & $-31,8$ & $-36,062$ & 3,0865 \\
\hline
\end{tabular}

Tabel 2. menunjukkan bahwa terjadi perubahan warna sebelum dan setelah 7 hari perendaman larutan coklat pada basis gigi tiruan nilon termoplastis.Terjadi penurunan rata-rata nilai value, peningkatan rata-rata nilai chroma, dan nilai hue.
Tabel 3. Hasil uji normalitas nilai warna basis gigi tiruan resin akrilik polimerisasi panas dan nilon termoplastis sebelum dan setelah perendaman dengan larutan coklat selama 7 hari menggunakan Shapiro Wilk

\begin{tabular}{lllll}
\hline & & \multicolumn{3}{c}{$p$ value } \\
\cline { 3 - 5 } & & Value & Chroma & Hue \\
\hline Resin Akrilik Polimerisasi Panas & & & \\
& Sebelum & 0,487 & 0,212 & 0,200 \\
& Setelah & 0,997 & 0,953 & 0,808 \\
Nilon Termoplastis & & & & \\
& Sebelum & 0,964 & 0,426 & 0,880 \\
& Setelah & 0,441 & 0,235 & 0,024 \\
\hline
\end{tabular}

Tabel 3. menunjukkan hasil uji normalitas data menggunakan Shapiro Wilk. Hasil uji normalitas menunjukkan distribusi data normal $(\mathrm{p}>0,05)$, namun analisis data dilanjutkan dengan menggunakan uji non parametrik karena skala data adalah ordinal.

Tabel 4. Hasil perbandingan nilai warna basis gigi tiruan resin akrilik polimerisasi panas sebelum dan setelah perendaman dengan larutan coklat selama 7 hari menggunakan uji Wilcoxon

\begin{tabular}{cc}
\hline & \multicolumn{1}{c}{$\boldsymbol{p}$ value } \\
\cline { 2 - 2 } & Resin Akrilik Polimeisasi Panas \\
\hline Value & 0.000 \\
Chroma & 0.003 \\
Hue & 0.001 \\
\hline
\end{tabular}

Tabel 4. menunjukkan hasil uji Wilcoxon perbandingan nilai warna basis gigi tiruan resin akrilik polimerisasi panas sebelum dan setelah perendaman dengan larutan coklat selama 7 hari dengan nilai signifikansi $\mathrm{p}<0,05$. Hasil menunjukkan bahwa terdapat perubahan stabilitas warna yang bermakna berupa penurunan rata-rata nilai value, peningkatan rata-rata pada nilai warna chroma, dan hue setelah direndam dalam larutan coklat selama 7 hari.

Tabel 5. Hasil perbandingan nilai warna basis gigi tiruan nilon termoplastis sebelum dan setelah perendaman dengan larutan coklat selama 7 hari menggunakan uji Wilcoxon

\begin{tabular}{cc}
\hline & p value \\
\cline { 2 - 2 } & Nilon Termoplastis \\
\hline Value & 0.000 \\
Chroma & 0.000 \\
Hue & 0.000 \\
\hline
\end{tabular}


Tabel 5. menunjukkan hasil uji Wilcoxon perbandingan nilai warna basis gigi tiruan nilon termoplastis sebelum dan setelah perendaman dengan larutan coklat selama 7 hari dengan nilai signifikansi $p<0,05$. Hasil menunjukkan bahwa terdapat perubahan stabilitas warna yang bermakna berupa penurunan rata-rata nilai value, peningkatan rata-rata pada nilai warna chroma, dan hue setelah direndam dalam larutan coklat selama 7 hari. Setelah itu dilakukan uji Mann Whitney untuk menguji perbandingan perubahan nilai warna pada kedua kelompok basis gigi tiruan resin akrilik polimerisasi panas dan nilon termoplastis yang direndam dalam larutan coklat selama 7 hari.

Tabel 6. Hasil perbandingan perubahan nilai warna basis resin akrilik polimerisasi panas dan nilon termoplastis sebelum dan setelah perendaman dengan larutan coklat selama 7 hari menggunakan uji Mann Whitney

\begin{tabular}{ccccc}
\hline & Mean & $\begin{array}{c}\text { Mean } \\
\text { Rank } \\
\text { Akilik }\end{array}$ & $\begin{array}{c}\text { Mean } \\
\text { Rank } \\
\text { Nilon }\end{array}$ & p value \\
\hline Value & -3.450 & 20,88 & 12,12 & 0.008 \\
Chroma & 4.468 & 9,75 & 23,25 & 0.000 \\
Hue & 7.487 & 8,81 & 24,19 & 0.000 \\
\hline
\end{tabular}

Tabel 6 menunjukkan hasil Uji Mann Whitney pada nilai value, chroma, dan hue pada basis gigi tiruan resin akrilik polimerisasi panas dan nilon termoplastis yang direndam dalam larutan coklat selama 7 hari dengan nilai signifikansi $p=0,000 \quad(p<0,05)$. Hal ini menunjukkan bahwa terdapat perbedaan yang bermakna yang diperlihatkan pada nilai value, chroma dan hue plat resin akrilik polimerisasi panas dan nilon termoplastis setelah direndam dengan larutan coklat selama 7 hari. Penurunan rata-rata nilai value pada kelompok resin akrilik polimerisasi panas lebih besar dari pada resin nilon termoplastis, peningkatan rata-rata nilai chroma pada kelompok resin nilon termoplastis lebih besar dari pada resin akrilik polimerisasi panas, peningkatan rata-rata nilai hue pada kelompok resin nilon termoplastis lebih besar dari pada kelompok resin akrilik polimerisasi panas. Dengan demikian pula dapat dikatakan bahwa terdapat perbedaan stabilitas warna yang bermakna antara basis gigi tiruan resin akrilik polimerisasi panas dan nilon termoplastis, dan resin akrilik polimerisasi panas memiliki stabilitas warna yang lebih stabil dibandingkan dengan resin nilon termoplastis.

\section{PEMBAHASAN}

Stabilitas warna pada basis gigi tiruan ialah salah satu karakteristik utama yang sangat penting karena melibatkan masalah estetik. Teknik dan pemilihan bahan harus dipastikan agar meminimalisir terjadinya diskolorasi. Banyak faktor yang dapat menyebabkan terjadinya diskolorasi pada basis. Faktor instrinsik adalah perubahan kimia pada bahan itu sendiri yaitu proses polimerisasi yang tidak sempurna sedangkan faktor ekstrinsik adalah munculnya stain akibat absorpsi bahan pewarna seperti dari kopi, coklat, nikotin, minuman ringan dan larutan kumur. ${ }^{7-9}$

Berdasarkan hasil penelitian yang telah dilakukan, rata-rata warna plat gigi tiruan resin akrilik polimerisasi panas sebelum dan setelah perendaman dengan larutan coklat selama 7 hari menunjukkan terjadi perubahan warna. Perubahan yang terjadi yakni penurunan nilai rata-rata value (dari 1,2700 menjadi 1,2516), peningkatan rata-rata nilai chroma (dari 0,6021 menjadi 2,0775)dan nilai hue (dari 1,0224 menjadi 1,8741). Hasil perbandingan nilai warna basis gigi tiruan resin akrilik polimerisasi panas menggunakan uji Wilcoxon menunjukkan hasil yang signfikan ( $\mathrm{p}$ value $<0.05$ ) senilai 0.000 untuk value, 0.003 untuk chroma, dan 0.001 untuk hue. Pengaruh perubahan ini terjadi disebabkan karena adanya sifat porositas pada resin akrilik yang menyebabkan penyerapan larutan kedalam resin akrilik. Penelitian sesuai yang dilaukan oleh Naini (2014) menjelaskan bahwa akrilik mempunyai sifat porositas yang dapat menyerap berbagai jenis bahan minuman, makanan maupun bahan kmia. Penyerapan dimungkinkan oleh polaritas molekul polimetil metekrilat yang memiliki mekanisme difusi. Penjelasan selanjutnya yang dikutip oleh Annusavice (2013) menjelaskan perubahan warna yang terjadi disebabkan oleh berbagai macam faktor, antara lain ukuran sampel untuk penelitian, mikroporositas sampel dan lamanya bahan sampel yang berkontak dengan larutan. Semakin luas ukuran sampel yang terkena larutan maka semakin besar perubahan yang terjadi. Mikroporositas menentukan terjadinya penempelan partikel warna daerah yang porus. ${ }^{2,10}$

Berdasarkan hasil penelitian yang telah dilakukan, rata-rata warna basis gigi nilon termoplastis sebelum dan setelah perendaman dengan larutan coklat selama 7 hari menunjukkan terjadi perubahan warna. Perubahan yang terjadi yakni peningkatan nilai ratarata value (dari 2,1702 menjadi 4,4113), peningkatan nilai rata-rata chroma (dari 1,6715 menjadi 2,8846) dan penuruan pada hue (dari 4,0557 menjadi 3,0865). Hasil perbandingan nilai warna basis gigi tiruan nilon termoplastis uji Wilcoxon menunjukkan hasil yang signfikan (p value $<0.05$ ) senilai 0.000 untuk value, 0.000 untuk chroma, dan 0.000 untuk hue. Pengaruh perubahan ini terjadi disebabkan oleh sifat fisik seperti pengerutan, perubahan dimensi dan penyerapan air. Penyerapan utama pada larutan yang tinggi akan diserap oleh bahan yang terbuat dari nilon. Penelitian sebelumnya oleh Naini (2014) menjelaskan bahwa cairan seperti coklat akan terserap oleh nilon termoplastis yang akan terjadi difusi (perpindahan suatu substansi melalui rongga). Nilon termoplastis memiliki daya penyerapan air maupun larutan yang 
tinggi, sehingga banyaknya konsentrasi rantai amide pada resin membuat perubahan warna yang terjadi pada bahan basis nilon termoplastis. Hal ini juga berpengaruh oleh kandungan larutan coklat yaitu tanin yang mampu menimbulkan perubahan warna. Komponen ini mengalami aliran kapiler secara difusi oleh karena penetrasi fisik dan pigmen antara molekul latik ke dalam nilon termoplastis. ${ }^{10,11}$

Hasil perbandingan perubahan nilai warna basis gigi tiruan resin akrilik polimerisasi panas dan nilon termoplastis sebelum dan setelah perendaman dengan larutan coklat selama 7 hari menggunakan uji Mann Whitney menunjukkan hasil yang signifkan ( $\mathrm{p}<$ 0.05 ) untuk value senilai 0.008 , chroma 0.000 dan hue 0.000 . Hal ini menunjukkan bahwa terdapat perbedaan yang bermakna yang diperlihatkan pada nilai value, chroma dan hue plat resin akrilik polimerisasi panasdan nilon termoplastis setelah direndam dengan larutan coklat selama 7 hari. Penurunan rata-rata nilai value pada kelompok resin akrilik polimerisasi panas lebih besar dari pada resin nilon termoplastis, peningkatan rata-rata nilai chroma pada kelompok resin nilon termoplastis lebih besar dari pada resin akrilik polimerisasi panas, peningkatan rata-rata nilai hue pada kelompok resin nilon termoplastis lebih besar dari pada kelompok resin akrilik polimerisasi panas. Dengan demikian pula dapat dikatakan bahwa terdapat perbedaan stabilitas warna yang bermakna antara basis gigi tiruan resin akrilik polimerisasi panas dan nilon termoplastis, dan resin akrilik polimerisasi panas memiliki stabilitas warna yang lebih stabil dibandingkan dengan resin nilon termoplastis. Resin nilon termoplastis memiliki daya penyerapan air maupun larutan yang tinggi dibandingkan dengan resin akrilik, sehingga banyaknya konsentrasi rantai amide pada resin membuat perubahan warna yang terjadi pada bahan basis nilon termoplastis. Hal ini juga berpengaruh oleh kandungan larutan coklat yaitu tanin yang mampu menimbulkan perubahan warna. Komponen ini mengalami aliran kapiler secara difusi oleh karena penetrasi fisik dan pigmen antara molekul latik kedalam nilon termoplastis. ${ }^{10,11}$

\section{KESIMPULAN DAN SARAN}

Terdapat perbedaan stabilitas warna antara basis gigi tiruan resin akrilik polimerisasi panas dan resin nilon termoplastis, yaitu resin akrilik polimerisasi panas lebih stabil terhadap perubahan warna. Kekurangan dari penelitian ini adalah jumlah sampel yang sedikit dan waktu perendaman yang mungkin lebih bervariasi. Saran bagi peneliti lainnya agar dapat dilakukan penelitian serupa dengan waktu berbeda dan menggunakan variabel yang lebih bervariasi. Bagi pengguna gigi tiruan agar memperhatikan faktorfaktor yang dapat menyebabkan perubahan warna pada gigi tiruan seperti minuman yang dikonsumsi dan kebersihan mulut.

\section{DAFTAR PUSTAKA}

1. Craig RG, Power JM. Restorative Dental Materials. $11^{\text {th }}$ ed. St Louis: Mosby; 2002: 636-89

2. Anusavice KJ, Shen C, Ralph Rawls H. Philips'Science of Dental Materials. 12 ${ }^{\text {th }}$ ed. Missouri: Elsevier; 2013: 29-61, 192-219, 202-211, 474-489

3. Manappallil JJ. Basic Dental Materials. $2^{\text {nd }}$ ed. New Delhi: Jaypee Brothers Medical Publishers (P); 1998: 98-137

4. Phillips RW. Buku Ajar Ilmu Kedokteran Gigi. Edisi 10. Jakarta: EGC; 2003: 223-234

5. Negrutiu M, Sinescu C, Romanu M, Pop D, Lakatos S. Thermoplastic Resins for Flexible Framework Removable Partial Dentures.TMJ. 2005; 3(1): 1-5:[L"]

6. Ditolla M. Valplast: Flexible, Aesthetic Partial Dentures. Chairside Perspective. April 2005; 5(1): 1-6

7. Kortrakulkij K. Effect of Denture Cleanser on Color Stability and Flexural Strength of Denture Base Materials. [Thesis]. Thailand: Mahidol University. 2008: 1-73. SE-

8. Faltermeier A, Rosentritt M, Reicheneder C, Behr M. Discolouration of Orthodontic Adhesives Caused by Food Dyes and Ultraviolet Light. Eur J orthodont. 2008; 30: 89-93

9. Celik C, Yuzugullu B, Erkut S, Yamanel K. Effects of Mouth Rinses on Color Stability of Resin Composites. Eur J dent. 2008; 2: 247-253

10. Amiyatun Naini. Perbedaan Stabilitas Warna Bahan Basis Gigi Tiruan Resin Akrilik dengan Resin Nilon Termoplastis terhadap Penyerapan Cairan. Stomatognatic (J.K.G Unej). 2012; 9(1): 28-32

11. Amiyatun Naini. Pengaruh Larutan Coklat (Theobroma cacao L) terhadap Stabilitas Warna Basis Gigi Tiruan Resin Nilon Termoplastis. Dentika Dental Journal. 2014; 8(1): 53-57 